\section{AN ECONOMIST'S \\ PROPOSAL FOR THE STUDY OF THE TRANSLATION PROFESSION IN SOUTHEAST ASIA}

\section{Andy Lung Jan Chan ${ }^{1}$}

\begin{abstract}
The translation profession in the Southeast Asia context has not been adequately investigated in a methodologically rigorous manner. One reason is the focus of Translation Studies scholars on textual end products, mostly of canonical literature. Another reason, perhaps more importantly, is the absence of an appropriate theoretical and conceptual framework (or the inadequacy of current paradigms) to look into the translation agents. This paper begins by reviewing the existing research work on the translation profession in the Southeast Asian context. Perhaps not surprisingly, there is not much, and some of the material found is casual and cursory discussion on personal weblogs and websites of translation companies. In view of this, I would suggest how economic science can be used as an analytical framework for studying the translators and various other stakeholders in the region and particularly how the translation profession can be investigated from macro, micro and meso levels. The last section of this paper points out some epistemological
\end{abstract}

\footnotetext{
${ }^{1}$ Assistant Professor, Department of

Translation, Lingnan University, Hong Kong.
}

strengths and weaknesses of any such approach.

\section{Introduction}

Translation Studies (TS) is a relatively young academic interdiscipline with its formal founding dating to the early 1970 s in Belgium and the Netherlands. In its early development and well into the 1980s and 1990 s, the focus of this academic field was on textual end products and most such research revolved around canonical literature. In recent decades, more attention has been paid to translators and the various translation agents involved in the translation process. Indeed, there has been a growing number of research articles and monographs devoted to the study of the translator's agency, habitus and networks (e.g. Wolf and Fukari 2007; Milton and Bandia 2009; Abdallah 2012).

Looking back to almost twenty years ago, Andrew Chesterman (1998) wrote, "Translation Studies ... [is] not concerned enough with the real problems at the messy grassroots of life in a big translation company" (96, italics mine). In another article, "The Name and Nature of Translator Studies" (2009), he argued that translation research should take people as the primary and explicit focus as well as the central concept of research questions. In particular, he believed that the study of the sociology of translators should cover "issues such as the status of (different kinds of) translators in different cultures, rates of pay, working conditions, role models and 
the translator's habitus, professional organizations, accreditation systems, translators' networks, copyright and so on" (Chesterman 2009: 16).

In view of this, in recent years, there have been more papers and books devoted to the sociological study of translators and other translatorial agents and some scholars have even pointed out that these represent a "social" turn in the TS. For example, Steve Berneking writes in his article "A Sociology of Translation and the Central Role of the Translator":

Translation studies scholars have recently recognized a definitive "social" turn in the field, leading to the emergence of a sociology of translation which recognizes that translation happens in the mind of translators as social beings who function in multiple roles and negotiate meanings, situated within an environment of social and cultural dimensions. A sociology of translation shifts the focus from texts to the translators, their roles, social networks and lasting effects on society. (Berneking 2017: 265)

However, in our interdiscipline, the emphasis seems to be still on the "star" literary translators rather than on those literary translators who are not as famous and business translators who are generally believed to be working long hours and earning a meagre income. There are two possible reasons for this. First, the data of non-literary professional translators is usually difficult to obtain. Large multinational language service providers
(LSPs) seldom allow researchers to go in and carry out research. The second reason, probably more important, is the "messiness" one may encounter when attempting to study the translation profession. Here "messiness" may mean that a conceptual theoretical framework to analyse the translation profession is lacking. Luckily, in recent years, many researchers have found the concepts espoused by sociologists such as Bourdieu, Latour and Luhmann useful to investigate the behaviour of professional translators and other translatorial actors. This paper points out an alternative conceptual framework and argues that an economic perspective may also be fruitful to TS scholars in their study of the translation profession, if economics is understood as the study of human behaviour in which choices are made under the conditions of scarcity.

To be more specific, an agenda for the study of the translation profession in the Southeast Asian context is put forward in this paper. First, I review the existing research work on the translation profession in the Southeast Asian context. Then, I discuss how economic science can be used as a framework for studying the translators and various other stakeholders in the region and in particular, how the translation profession can be investigated from macro, micro- and meso-economic levels. The last section of this paper points out some epistemological strengths and weaknesses of such an approach. 


\section{Review of the research literature on the translation profession in the Southeast Asian context}

Though accounting for only 3\% of the world's total land area, Southeast Asia is the third most populous geographical region in the world, after South Asia and East Asia. It is also important and unique both economically and linguistically. Economically, the Gross Domestic Product at purchasing power parity for Association of Southeast Asian Nations (ASEAN) countries has grown from US $\$ 7,052$ in 2007 to US\$11,009 in 2015 (ASEAN 2016) and Cambodia, Laos, Myanmar and Vietnam, which make up the Greater Mekong Region, enjoy growth rates even higher than those of ASEAN countries as a whole. Linguistically, some 60 other languages are spoken in Thailand while there are 137 living languages in Malaysia, that boasts a linguistic diversity index of 0.758 which is the second highest in ASEAN after Indonesia (Chan and Liu 2013).

The ten countries in ASEAN (Brunei, Cambodia, Indonesia, Laos, Malaysia, Myanmar, the Philippines, Singapore, Thailand and Vietnam) are frequently mentioned in the media and studied by academics since ASEAN has been striving for closer economic and cultural bonds in recent years. In what follows, three papers concerning the translation profession in Southeast Asia are discussed.

The first journal paper reviewed here is "The translator status, the translation market and developing economies: A preliminary study of ASEAN countries", by Chan and Liu (2013), published in the Southern African Linguistics and Applied Language Studies' special issue on Translation in Developmental Contexts. The paper uses the macro-economic framework (discussed later in this article) to study the relationship between translator status, the translation market and the economic development of the ten countries in ASEAN. Online questionnaires were sent to the translators, interpreters and other translation-related professionals and quantitative and qualitative data was collected. The result, perhaps as one of the reviewers aptly pointed out, "is nothing earth-shattering", i.e. the status of translators is quite low and the respondents believe that the absence of a certification system and of a standard practice is hardly beneficial both for the development of the translation industry and translators themselves in this region. Moreover, as there are differences in the linguistic situations of the various ASEAN countries, their translation markets and professions can be quite distinctive, so studies on a country level are much welcome.

The second paper indeed focuses on the translation profession in a particular country in Southeast Asia, that is Malaysia, which has the second highest linguistic diversity index in ASEAN with 137 living languages. In "The translation profession in Malaysia: The translator's status and selfperception", Myoung Sook Kang and Krishnavanie Shunmugam (2014) quite rightly point out, "Although there is clearly a substantial amount of translation work being carried out in Malaysia.... Little is really known about the goings-on in the Malaysian translation scene" (192). The 
research of the two scholars was guided by hermeneutic phenomenology as their method of inquiry. Both quantitative and qualitative data was elicited from 50 translators who are members of the Malaysian Translators' Association (MTA) and Malaysian National Institute of Books and Translation. The study seems to echo the assertion of Sela-Sheffy and Shlesinger (2008) that translation is a pink-collar profession, as the majority of the respondents selected randomly for this study are female. Not all Malaysian translators in this sample possess the qualification of at least a certificate or a diploma in translation, and they held the view that education is not an important factor in their practice as translators. Regarding remuneration, Malaysian translators in the survey were being paid rates recommended by the MTA. Some revealed that translating can be a lucrative profession if one demonstrates competence and works for large multinational companies. However, the respondents reckoned that the competition from amateur translators affected the credibility and exclusivity of the profession and it was concluded that " $t]$ his clearly puts the professional translators at a disadvantage, as they have no way of securing themselves against competition from amateur translators" (203). Kang and Shunmugam (2014) put forward two recommendations based on their findings: (1) to form a professional body to represent translators in Malaysia; (2) to educate the public on the merits of engaging professional translators to do translation work and on the meaningful contribution translators make to society.
The third paper discussed here is the case study of Thailand. Tongtip Poonlarp and Nattharath Leenakitti (2016), in a very recent article in the Journal of Language and Culture, analysed 95 job advertisements for translators posted in eight online recruitment websites collected between $31^{\text {st }}$ January and $21^{\text {st }}$ February, 2012. This research is an interesting investigation into the needs and expectations that employers have of translators in Thailand, the second largest economy in Southeast Asia. The authors found that, although two-thirds of the job advertisements look for translators proper, one-third seek candidates to fill hybrid positions, such as translator-administrators and translator-secretaries. This echoes my survey of job advertisements in China where some companies look for "a master of all trades: from 'tackling noncompliance incidents' (which should be the work of a legal counsel) to the more mundane tasks of printing, photocopying and record keeping" (Chan 2017). In the Thai classifieds' search for translators, the monthly salary range is also astoundingly large: from the lowest 9,500 Thai Baht (US\$284) for "Translator with Other Duties" to the highest 70,000 Thai Baht (US\$2,098) for "Translator-Interpreter". According to Poonlarp and Leenakitti (2016), the job advertisements in Thailand also show that there are general misconceptions about the translation profession, such as "anyone who knows that language can translate' and 'the translator is an interpreter".

The above papers use interesting empirical research instruments (e.g. surveys, interviews and job advertisements) to 
investigate the translation profession and the translation market. However, the above review cannot be regarded as comprehensive and exhaustive. In fact, there is also much discussion about the Southeast Asian translation market on personal weblogs and websites of translation companies. For example, Emil Atanassov, the general manager (Asia Pacific) of a multinational language service provider established in 1987, wrote in his blog in January 2012 that gaming localisation would be a new trend for the translation profession and translators need to adapt to an age of artificial intelligence in which machine translation may play a more important role since there is a greater demand for game translation within a short turnaround time. On the other hand, it is also likely that some of the articles on the translation profession in Southeast Asia are only available in local languages. It would be desirable if these could be translated into English so that the situation of the translation markets could be better known to an international audience. In what follows, the author uses an analytical framework of economics so that researchers in Southeast Asia may have a clearer lens through which to investigate the complexities and delicacies of the translation profession in the region.

\section{Economics as an analytical framework}

"What has economics to do with translation?" one might ask. To most people, economics, a sub-discipline of social sciences, is concerned with issues like household consumption decisions, financial investment analysis and company and government budgets. Webster's New World Dictionary (2003) defines economics as a social science or business discipline that "deals with the production, distribution and consumption of wealth, and with the various related problems of labor, finance and taxation" (207).

However, quite a number of economists believe that the scope of analysis of economics in a conventional sense is too narrow. Some so-called heterodox economists have used the analytical tools of economics to study love and marriage (Friedman 1990; Grossbard-Schechtman 1993), childbearing (Becker 1981), as well as crime and punishment (Becker 1968; Posner 1992). In fact, the 1992 Nobel Prize in Economic Science was awarded to the University of Chicago economics (and sociology) professor, Gary S. Becker, for "having extended the domain of microeconomic analysis to a wide range of human behavior and interaction, including non-market behavior" (Nobel Foundation 1992: 1).

Therefore, economics can be understood generally as the study of any human actions in which cost and benefit considerations are involved. Translating, one of the oldest and most ubiquitous human activities, has great potential for being investigated from an economic approach. Pym, Grin, Sfreddo and Chan (2012) point out in a report funded by the European Commission entitled The Status of the Translation Profession in the European Union that "Translation has received very little attention in economics". In fact, the reverse is also true: economics has received very little attention from TS. In view of this, the 
commissioned report has employed a microeconomic model to examine the translation market in Europe. In the following, we will go a step further by outlining a proposal for the study of the translation profession in Southeast Asia on macro-, micro- and meso-levels.

\section{The study of the profession in Southeast Asian at a macro-level}

Macro-economics is a branch of economics dealing with economic performance, structure and behaviour of an aggregate level. Traditionally, macro-economists are concerned with economic growth (calculated by gross domestic product or more recently, human development index). Economics scholars believe economic growth can be achieved by a number of means such as consumption, investment, government expenditure and net exports (exports minus imports). In recent years, the countries of ASEAN, a bloc of ten member states formed by Indonesia, Malaysia, the Philippines, Singapore and Thailand in 1967 and later joined by Brunei, Myanmar (Burma), Cambodia, Laos and Vietnam, have become the "factories" of the world or outsourcing centres of some developed countries. Direct foreign investment is also very high in these countries. Tourism, which is a form of invisible trade, is booming and the World Tourism Organization (2002) lists Southeast Asia as one of the three fastestgrowing tourism regions in the world today. Also, the governments have been investing massively in large-scale infrastructure projects. Chan and Liu's (2013) work can be viewed as a preliminary attempt to investigate the relationships between translator status, the national translation market and national economic development. However, one of the greatest shortcomings of their paper is that, at a country level, the number of respondents in each ASEAN country was less than five (except for Thailand and Vietnam). In future, researchers will be able to investigate the translation profession in Southeast Asia at a country level with a much larger sample and in greater depth as there may be significant differences between the national translation markets in the region. Take Thailand and Vietnam as examples. Quite a substantial proportion of their populations does not have a high command of English though the demands for the latest scientific and technological knowledge (often disseminated in English) are really great. On the other hand, in other ASEAN countries (most notably Singapore), most people seem to have a high proficiency in the English language and can readily access the latest developments in science and technology through the international lingua franca of English. As a result of this, their need for translation services can be quite different.

Macroeconomics often extends to the international sphere, because domestic markets are linked to foreign markets through trade, investment and capital flow. Therefore, TS scholars may also study the translation profession in Southeast Asia using the "factor price equalisation theorem". Developed by another Nobel Prize winning economist, Paul A. Samuelson (1915-2009), the theorem states that international trade in commodities and services equalises the price of identical factors of production, 
such as the wage rate or the return on human capital, across countries. The relevance of this for professional translators is that, due to the advent of information, communication and translation technologies, a lot of translation work is outsourced or even crowdsourced to the Southeast Asian countries with lower wages. Future research work may concentrate on the effect of outsourcing and crowdsourcing on translation rates and translator status. Currently, what we have seems to be only anecdotal evidence.

\section{The study of the profession in Southeast Asian at a micro-level}

Micro-economics studies how individuals behave and interact under constraints. Homo economicus, or economic humans, are believed to maximise utilities (which can be monetary and/or non-monetary) under constraints. Translators are decision makers who make a large number of linguistic (e.g. the use of dictionaries and computer-aided translation) and nonlinguistic decisions (e.g. time management) during the translation process. In the Southeast Asian context, we can investigate the professional backgrounds, job profiles, as well as the monetary and non-monetary motives of the translators. Data can be obtained from interviews with translators regarding the linguistic and extra-linguistic decision-making processes in their professional work and the motives and constraints behind such processes. Possible analytical frameworks include Zionts' (1979) multiple-criteria decision analysis (MCDA) and Johnson and Payne's (1985) choice strategies regarding effort and accuracy. While there are similarities between economic and sociological approaches to the study of translators, a fundamental difference between these two approaches is that economics puts forward the assumption of rational individuals (in this context defined to be actors who maximise their own utility) under constraints while sociology seems to have less stringent assumptions about human behaviour.

Another important area for research for TS scholars is to look into the translation "markets" in Southeast Asia. According to Mankiw's (2015) Principles of Economics, a popular university-level textbook on economics, a market is a medium in which a group of sellers and buyers of particular goods or services interact in order to facilitate an exchange. This medium may be physical or virtual and sellers and buyers can engage in exchange activities either directly or indirectly through mediating agents. Two important concepts in the economic analysis of a market are supply and demand. Supply is the relationship between the price of goods and the quantities supplied; in other words, how many goods or services a seller is willing to supply at different given prices. Generally speaking, all things being equal, a seller will be willing to supply more at the price higher and vice versa. Demand depicts the relationship between the price of a goods and services and the quantity demanded. When the price is lower, a buyer normally tends to purchase more, ceteris paribus. Supply and demand are sometimes referred to as the two blades of a pair of scissors, and they work together to determine the market price in a free economy. 
The concepts of supply, demand and market price can be used to analyse the translation service market. In the case of translation, the "sellers" or "suppliers" of translation services may include government translators, in-house translators and freelancers who work fulltime or part-time, and the "buyers" or "demanders" of such services are various and varied, including different levels of government that need to fulfil their commitments to official languages or to uphold the linguistic rights of new immigrants. For example, in Chan's article on the Chinese translation market as an entry in the The Routledge Handbook of Chinese Translation (2017), it was pointed out in the Report on China's Language Services Industry 2010 published by the Translators Association of China that there were 1.2 million active practitioners in the language service industry in China, 640,000 of whom were translators (5.8 per cent). In this market, the decline of salaried translators and the rise of electronic translator marketplaces, defined as an environment (usually virtual and online) in which translation service buyers and sellers exchange information and do business, has led to a faster turnaround and a drop in the translation rate. In the Southeast Asian context, according to the report Digital in Southeast Asia (2017), online connectivity is also growing at an impressive rate throughout the region, and the number of Internet users in the region has increased by more than $30 \%$ - or 80 million new users - in the past 12 months alone. The online translator marketplace in Southeast Asia should be a topic for TS scholars interested in the development of the translation profession in the next decade.
On the other hand, in the Southeast Asian context, organisations such as ASEAN, the Asian Development Bank and Asia-Pacific Economic Cooperation could also be interesting case studies. In addition, the many private enterprises in Southeast Asia usually want to trade with other countries with a multilingual website or to simply project a better business and corporate image. Lastly, very little is known about translation agencies of various sizes in this part of the world.

\section{The study of the profession in Southeast Asian at a meso-level}

Some economists are not satisfied with this traditional strict dichotomy of macro- and micro-economics and have tried to put forward some alternatives. One of the more important and influential attempts has been Dopfer's. Dopfer, a professor of economics at the University of St. Gallen, Switzerland, together with Foster and Potts, introduced the concept of "meso-economics" (Dopfer, Foster and Potts 2004). The mesoeconomists believe that there ought to be an intermediate level of economic analysis, apart from the micro- and macro-level. The intermediate level of economic analysis studies various institutional arrangements and factors that facilitate or hinder the operations of such arrangements.

One of the areas of particular interest to meso-economists is information theory. The mechanics of information transmission leads to behaviour that is not easily explicable as micro- or macro-economic effects. I have applied several concepts in information theory such as "asymmetric information", "adverse selection" and 
"signal jamming" to look into the translation market (Chan 2005, 2013). To put it simply, in my analyses, translations are perceived as artefacts being produced and exchanged within a market where buyers (clients and vendor managers) lack complete information on the quality of the products they are purchasing. Here, the problem is that the person who needs a translation cannot fully judge the quality of the translation. In order for the translation market to function efficiently in an economic sense, some signaling devices (academic qualifications, professional certification, records of experience, etc.) are required so that buyers can be assured of quality. In recent years, there has been a mushrooming of translation programmes (at both the undergraduate and postgraduate level) in several Southeast Asia countries. For instance, in the city state of Singapore, various educational centres (e.g. the Singapore Chinese Chamber Institute of Business) offer diploma courses in translation while Singapore University of Social Sciences and the National University of Singapore offer Translation and Interpretation BA and MA programmes respectively. In 2016, Nanyang Technological University also launched its Master of Arts programme in Translation and Interpretation (Straits Times $22^{\text {nd }}$ January 2016). In Thailand, at least six universities (including Chulalongkorn University, Mahidol University and Thammasat University) are offering MA in Translation and/or Interpretation programmes.

On the other hand, there is also talk both within and outside academia about the setting up of translator certification mechanisms. To this end, TS scholars should not just investigate the effectiveness of such translation programmes and certification mechanisms at a curricular or structural level. Instead, more effort should be put into finding out how these signaling devices function to reduce the problem of asymmetric information and adverse selection currently observed in the Southeast Asian translation market. In economic jargon, a market with asymmetric information refers to one in which one side of the market has more information than the other side and this results in a market price lower than the fair price. In a translation service market, the situation is similar: it is usually difficult for service buyers or clients to assess the skills of a translator before any professional relationship has been established. Most of the time, service buyers or employers can only assess the quality of translation after they receive the translation or when it is used in actual communication acts for various purposes.

Because of the asymmetric information problem, translation service buyers cannot effectively distinguish between a good translator and a bad one when they need to recruit new translators for their work. Therefore, they tend to pay a price that is below the fair level. As a result, the good translators tend to leave the market and the bad translators may stay. This is basically what adverse selection means. The problem of asymmetric information and of adverse selection seems to exist in the translation market in general and in Southeast Asia's translation market in particular as the translation markets are of a fragmentary nature marked by many freelancers as well 
as small and micro enterprises. It might be difficult for employers and translation service buyers to distinguish the good translators from the bad ones.

\section{Conclusion and Limitations}

Pym (2015), in a paper entitled "Translation and economics: rational decisions, competing tongues, and measured literacy", points out that there are a number of basic methodological virtues for using economics to study translation. Three of them are discussed here.

Firstly, economic values are presumed to be quantifiable, and the adoption of an economic approach in TS may make many variables operationalisable. I am not trying to argue that all problems concerning translators and TS scholars can be reduced to monetary terms and that literary translators should be left out of the picture. In fact, literary translation has been the research focus of three language and culture economics scholars in Belgium and the United States in the literature journal Poetics ("The economics of literary translation: Some theory and evidence" by Ginsburgh, Weber and Weyers, 2011).

Secondly, economic modelling simplifies complex situations and allows for a degree of formalisation. In scientific inquiry, this is sometimes referred to as Occam's razor, which means that, among competing hypotheses, the one with the fewest assumptions should be selected. The preference for simplicity in the scientific method is based on the falsifiability criterion. For each accepted explanation of a phenomenon, there may be an extremely large number of possible and more complex alternatives. Since one can always burden failing explanations with ad hoc hypotheses to prevent them from being falsified, simpler theories are preferable to more complex ones because they are more testable. Pym points out: "The relation between asymmetric information and market disorder has something of the same aesthetic appeal. There is beauty in these ideas" (2015: 3). Here the ideas of asymmetric information and market disorder are considered to be beautiful probably because they are formalisable and testable and very few assumptions are needed.

Thirdly and perhaps most importantly is that economics adopts an empirical mode of study. In the economic way of thinking, we are able to test the relations in our conjecture against real-world data and see how well the model explains the data. If there are discrepancies between what we see and what we expect to see, we can always go back to amend our model so "a discovery process" is possible, and as Pym (2015) observes, such a process is "not really happening in Comparative Literature or Translation Studies at the time" (2015: $3-4)$.

It is important to point out that what I am trying to say is not that an economic approach should be used to replace the current sociological approaches to the study of the translation profession. After all, as McCloskey (1990a, 1990b) has pointed out on a number of occasions the certainty and predictability of economics may be a myth. Economic reasoning is just one kind of metaphor making or storytelling. George 
Stigler (1984), another laureate of the Nobel Memorial Prize in Economic Sciences, wrote: "So economics is an imperial science: it has been aggressive in addressing central problems in a considerable number of neighboring social disciplines, and without any invitations..." Although economics offers insights to TS scholars, we should be aware of its methodological and epistemological shortcomings. A proper conclusion and recommendation should be something like this: economic tools can be used to complement our current understanding of translation and translator behaviour and more research should be carried out on this front, particularly in the Southeast Asian context.

\section{References}

Abdallah, Kristiina. 2012. Translators in Production Networks. Joensuu: University of Eastern Finland.

Association of Southeast Asian Nations. 2016. ASEAN Economic Community Chartbook 2016. Jakarta, Indonesia: ASEAN Secretariat. $<\mathrm{http}$ ://www.aseanstats.org/wpcontent/uploads/2016/11/AECChartbook-2016-1.pdf>

Becker, Gary S. 1968. Crime and Punishment: An Economic Approach. Journal of Political Economy 76.2: 169-217.

Becker, Gary S. 1981. A Treatise on the Family. Cambridge, MA: Harvard University.
Berneking, Steve. 2017. A Sociology of Translation and the Central Role of the Translator. The Bible Translator 67(3): 265-281.

Chan, Andy Lung Jan and Christy Fung Ming Liu. 2013. The Translator Status, the Translation Market and Developing Economies: A Preliminary Study of ASEAN Countries. Southern African Linguistics and Applied Language Studies 31: 435-450.

Chan, Andy Lung Jan. 2005. Why are Most Translators Underpaid? Translation Journal 9.2: 3-12

Chan, Andy Lung Jan. 2013. Signal Jamming in the Translation Market and the Complementary Roles of Certification and Diplomas in Developing Multilateral Signaling Mechanisms. Translation \& Interpreting 5.1: 211-221.

Chan, Andy Lung Jan. 2017. Chinese Translation Market. The Routledge Handbook of Chinese Translation, edited by Chris Shei and Zhao-Ming Gao, pp. 257-271. London: Routledge.

Chesterman, Andrew. 1998. Description, Explanation, Prediction: A Response to Gideon Toury and Theo Hermans. Current Issues in Language and Society 1-2: 91-98.

Chesterman, Andrew. 2009. The Name and Nature of Translator Studies. Hermes 42: 13-22. 
Digital in Southeast Asia. 2017. We are Social and Hootsuite.

$<$ https://wearesocial.com/specialreports/digital-southeast-asia-2017>

Dopfer, Kurt, John Foster and Jason Potts. 2004. Micro-Meso-Macro. Journal of Evolutionary Economics 14.3: 263279.

Friedman, David D. 1990. Economics of Love and Marriage. Price Theory: An Intermediate Text, 2nd ed. Cincinnati, $\mathrm{OH}$ : South-Western Pub.

Ginsburgh, Victora, Shlomo Weber and Sheila Weyers. 2011. The Economics of Literary Translation: Some Theory and Evidence. Poetics 39.3: 228-246.

Grossbard-Schechtman, Shoshana. 1993. A Theory of Marriage, Labor, and Divorce. Boulder, CO: Westview Press.

Johnson, Eric J. and John W. Payne. 1985. Effort and Accuracy in Choice. Management Science 31.4: 395-414.

Kang, Myoung Sook and Krishnavanie Shunmugam. 2014. The Translation Profession in Malaysia: The Translator's Status and Self-Perception. Journal of Language Studies 14.3: 191-205.

Mankiw, N. Gregory. 2015. Principles of Economics, 7th ed. Stamford, CT: Cengage Learning.

McCloskey, Deirdre N. 1990b. If You're So Smart: The Narrative of Economic
Expertise. Chicago, IL: University of Chicago Press.

McCloskey, Donald N. 1990a. Storytelling in Economics. Narrative in Culture: The Uses of Storytelling in the Sciences, Philosophy and Literature, edited by Cristopher Nash, pp. 5-22. London: Routledge.

Milton, John and Paul Bandia. (eds.). 2009. Agents of Translation. Amsterdam: Benjamins.

Nobel Foundation. 1992. The Sveriges Riksbank Prize in Economic Sciences in Memory of Alfred Nobel 1992 Press Release.

Poonlarp, Tongtip and Nattharath Leenakitti. 2016. What do Employers Want? A Study of Online Job Advertisements for Translators in Thailand. Journal of Language and Culture 35.2: 7-33.

Posner, Richard. 1992. Economic Analysis of Law. 4th ed. Boston: Little Brown.

Pym, Anthony, Grin, François, Sfreddo, Claudio and Chan, Andy Lung Jan. 2013. The Status of the Translation Profession in the European Union. London/New York: Anthem Press.

Pym, Anthony. 2015. Translation and Economics: Rational Decisions, Competing Tongues, and Measured Literacy. $<$ http://usuaris.tinet.cat/apym/online/ research_methods/2015_Translation and_economics.pdf> 
Sela-Sheffy, Rakefet and Miriam

Shlesinger. 2008. Strategies of Image-

Making and Status Advancement of

Translators and Interpreters as a

Marginal Occupational Group. Beyond

Descriptive Translation: Investigations

in Homage to Gideon Toury, edited by

Anthony Pym, Miriam Shlesinger and

Daniel Simeoni, pp. 81-90.

Amsterdam: John Benjamins.

Stigler, George J. 1984. Economics: The Imperial Science? The Scandinavian

Journal of Economics 86.3: 301-313

Straits Times. 2016. NTU Launches New

Translation Course.

$<$ http://www.straitstimes.com/

singapore/education/ntu-launches-new-

translation-course $>$

Webster's New World Dictionary. 2003.

4th ed. New York: Pocket Books.

Wolf, Michaela and Alexandra Fukari. (eds.). 2007. Constructing a Sociology of Translation. Amsterdam: Benjamins.

World Tourism Organization. 2002.

Tourism Highlights. Madrid: World Tourism Organization.

Zionts, Stanley. 1979 MCDM - If not a Roman Numeral, then What? Interfaces 9.4: 94-101. 